\title{
Evaluating the risk factors that link obesity and dental caries in 11-17-year-old school going children in the United Arab Emirates
}

\author{
Foroogh Abdalla Khadri ${ }^{1}$, Vellore Kannan Gopinath ${ }^{2}$, Mark P. Hector ${ }^{3}$, \\ Elizabeth S. Davenport ${ }^{4}$
}

Correspondence: Dr. Vellore Kannan Gopinath

Email: gopinathvk@yahoo.com

\begin{abstract}
'Department of Paediatric Dentistry, Sharjah Specialised Dental Centre, Ministry of Health and Prevention, Sharjah, UAE,

2Department of Preventive and Restorative Dentistry, College of Dental Medicine, University of Sharjah, Sharjah, UAE,

${ }^{3}$ School of Dentistry, University of Dundee, Dundee, UK, ${ }^{4}$ Center of Oral growth and Development (Paediatric Dentistry), Barts and The London School of Medicine and Dentistry, London, UK
\end{abstract}

\section{ABSTRACT}

Objective: The objective is to study the effect of obesity on dental caries among schoolchildren in Sharjah, United Arab Emirates. Materials and Methods: The sample comprised 803, 11-17-year-old schoolchildren. The study was in the form of a randomized cross-sectional manner. Method used was two questioners. The first assessed socioeconomic and general health and the second detailed their demographic, oral hygiene, and dietary habits. Dental examination included dental caries assessment using the World Health Organization 1997 criteria and gingival health valuation. Clinical examination consisted of height, weight, and body mass index (BMI). Data analysis was done by descriptive, univariate, and multiple regressions. Results: In this sample, $75 \%$ had dental caries and the mean decayed, missing, and filled teeth (DMFT) was 3.19 (standard deviation: 2.9). Obesity was seen in $15 \%$ of the adolescents and the mean BMI was 21 . The link between DMFT and BMI, when evaluated using univariate analysis, showed a significant correlation $(r=0.097, P=0.006)$, indicating that the rise in BMI by 10 points resulted in an increase in DMFT by 0.57 . However, in the multivariate analysis, a significant relationship was observed only between father's education $(P<0.001)$, adolescent's age $(P<0.001)$, gender $(P=0.008)$, ethnicity $(P=0.001)$, and soft drink consumption with DMFT while BMI showed a significant association with age $(P<0.001)$, school fees $(P=0.005)$, obesity in family $(P<0.001)$, and soft drink consumption $(P<0.001)$. Conclusions: Obesity and dental caries were not significantly associated. The most important predictor for obesity and dental caries was soft drink consumption.

Key words: Dental caries, obesity, soft drink consumption

\section{INTRODUCTION}

The shift toward modernization and growth in most part of the world, since the turn of the millennium,

\begin{tabular}{|l|l|}
\hline \multicolumn{2}{|c|}{ Access this article online } \\
\hline Quick Response Code: \\
\hline
\end{tabular}

has changed the diet pattern, work, and home lifestyle. ${ }^{[1]}$ This can be attributed to increased intake

This is an open access journal, and articles are distributed under the terms of the Creative Commons Attribution-NonCommercial-ShareAlike 4.0 License, which allows others to remix, tweak, and build upon the work non-commercially, as long as appropriate credit is given and the new creations are licensed under the identical terms.

For reprints contact: reprints@medknow.com

How to cite this article: Khadri FA, Gopinath VK, Hector MP, Davenport ES. Evaluating the risk factors that link obesity and dental caries in 11-17-year-old school going children in the United Arab Emirates. Eur J Dent 2018;12:217-24.

DOI: 10.4103/ejd.ejd_29_18 
of carbohydrates and reduced consumption of dietary fibers. ${ }^{[2]}$ This had been termed as "nutrition transition" is considered the main culprit for most of the systemic medical problems such as hypertension and diabetes. ${ }^{[3]}$ The development of obesity apart from being genetic can also be attributed toward the recent behavioral and environmental change. Such changes, creating an "obesogenic" environment, resulting from technological advances can be considered to influence the development of obesity. ${ }^{[4]}$

Incidence of obesity has increased significantly among the population of the Middle East region, ${ }^{[5-7]}$ including the United Arab Emirates (UAE). ${ }^{[8,9]}$ Resent research supports the objective of this study that is the relationship between dietary habits and obesity. ${ }^{[10]}$ Other studies demonstrate the effect of diet on periodontal health and dental caries. Based on the research available, we can assume that dental caries and obesity have common risk factors. ${ }^{[11,12]}$

Inadequate exposure to fluoride and increased consumption of sugar are considered as main causative factors for dental caries in developing countries as opposed to a significant decline of the same in developed countries, this is based on studies going back to 30 years. ${ }^{[1]}$ Unfortunately, incidence and prevalence of dental caries in the country of the UAE is not well documented over the recent years; there is one study which reported dental caries prevalence to be $54 \%$ among children aged 12 and $65 \%$ among schoolchildren aged 15 years. ${ }^{[13]}$ Although research has well established the link between obesity and various systemic chronic conditions, ${ }^{[4]}$ the same cannot be said for obesity and dental caries. Since variation in results was observed among studies conducted in different regions of the world. ${ }^{[14]}$ Thus, the main objective of this research study is to assess the link between obesity and dental caries among 11-17-year-old children living in the emirate of Sharjah. The age range selected in the present study indicates approximately the beginning to the end of adolescents, where children are exposed to risk factors due to sudden change in their lifestyle which could influence the development of obesity and dental caries.

\section{MATERIALS AND METHODS}

A cross-sectional method of research was used. The participants targeted were 11-17 years old in secondary school. Both genders were targeted. The participants were chosen from both private and public education sector in the emirate of Sharjah. Ten schools were selected of which six were private and four were public using random digit table. Out of the four public schools selected equal number were boys and girls schools (2 each). However, the private schools were classified according to the school fees as low, average, and high price. Two private schools from each category were selected considering proportional allocation. This research was approved by the Research Ethics Committee at Queen Mary University, London (Reference Number: QMREC2007/60). Valid and required approvals were sought from the Ministry of Health and Prevention and Ministry of Education in the UAE to conduct this study. The present research work was undertaken in agreement with the World Medical Association Declaration of Helsinki. Since all participants involved in this study were under 18 years of age, a written approval was attained from participants' parents/guardians, and this consent procedure was agreed by the research ethics board. The clarity of the translation of the Arabic questionnaire to English was tested in a pilot study. The present research is based on the theoretical models that is already well established. ${ }^{[15]}$ Based on this model, three variables and their interrelationships were examined in this study and they are distal explanatory (sociodemographic characteristics), intermediate explanatory (health behavior), and adolescent health outcomes (oral health status and body mass index [BMI]).

Malik and Bakir conducted a study in the UAE, among 5-17 years old, reporting obesity at 10\%. ${ }^{[16]}$ The sample size for the present study was calculated according to this, also taking into account, the study done on obesity among school going children in the UAE. ${ }^{[9]}$ The sample size was calculated, accordingly (based on these studies), using STATA 9 (Stata Corp LLC, Texas, USA). The difference in the mean decayed, missing, and filled teeth (DMFT) between obese and nonobese children was found to be 0.5 standard deviation (SD). ${ }^{[17]}$ To calculate this value, an alpha level of 0.05 (two-sided) and power of $90 \%$ were used. A rough size of 650 participants was deemed appropriate. This was considered a big enough sample size to provide small confidence interval for the different outcomes. However, taking nonresponse and refusals into consideration, a sample size of 803 participants was confirmed. Participants in whom obesity was considered to be due to systemic factors were not included in the present study. Ten schools were randomly chosen using random digit table. Both private (6) and public (4) sectors were included in the study.

European Journal of Dentistry, Volume 12 / Issue 2 / April-June 2018 
Separate questionnaires were constructed for the participants and their guardians. The questionnaire was developed to obtain wide variety of variables from both participants and their guardians. Adolescent questionnaires were used to detail and assess the demographics, their diet and physical activity, oral hygiene status, and psychological behavior. The questionnaire for the guardians focused on the socioeconomic status and medical history. This was followed by oral examination to assess dental caries using DMFT index according to the World Health Organization criteria, ${ }^{[18]}$ and oral cleanliness was measured using the British Association for the Study of Community Dentistry (BASCD) criteria. $^{[19]}$ Oral examination was performed under artificial light with the participant sitting up straight and facing the principal investigator. Disposable instruments were used for oral examination. Clinical data were collected based on two assessment forms. Initial height and weight were recorded using anthropometric measures using a digital weight and height scale. Calculation of BMI was based on the formula, BMI $=$ Weight $(\mathrm{kg}) /$ Height $\left(\mathrm{m}^{2}\right)$.

Statistical for the present data was done by IBM SPSS statistics for Windows, version 20.0, IBM Corp., Armonk, NY, USA, and descriptive analysis of the sample was performed. Whereas univariate analysis method was used to describe the relationship between explanatory variables and their outcomes, multivariate analysis helped to determine the joint effect of independent variables on dependent variables. Variables with significance at $5 \%$ level $(P<0.05)$ were deemed as risk factor.

\section{RESULTS}

The total number of participants in the present study was 803 out of which $50 \%$ were males. Nearly $40 \%$ were UAE nationals and $66 \%$ were attending private schools in the emirate of Sharjah. Tables 1 and 2 show the demographic distribution of the participants. Relationship between behavioral characteristics (diet, oral hygiene status, and physical activity) and demographics proved age, gender, and ethnicity to be important variables. According to the diet chart, $51 \%$ of the participants were reported to have three square meals (including breakfast) whereas $87 \%$ skipped the morning breakfast. The authors found that with the increase in age, consumption of dietary products such as milk, fruits, and vegetables reduced significantly, whereas soft drink consumption increases. Differentiation

\begin{tabular}{lc}
\multicolumn{2}{l}{ Table 1: Description of the study sample } \\
\hline Variable & Mean (SD) / $\boldsymbol{n}$ (\%) \\
\hline Age & $12.8(1.4)$ \\
Mean (SD) & 13 \\
Median & \\
Age (years), $n$ (\%) & $17(2.1)$ \\
10 & $146(18.2)$ \\
11 & $169(21)$ \\
12 & $223(27.8)$ \\
13 & $176(21.9)$ \\
14 & $46(5.7)$ \\
15 & $20(2.5)$ \\
16 & $6(0.7)$ \\
17 & \\
Gender, $n(\%)$ & $406(50.5)$ \\
Male & $396(49.4)$ \\
Female & \\
Nationality, $n(\%)$ & $325(40.5)$ \\
Emiratis & $278(34.6)$ \\
Other Arabs & $135(16.8)$ \\
Indians & $65(8.1)$ \\
Others & \\
School type, $n(\%)$ & $269(33.5)$ \\
Public & $534(66.5)$ \\
Private & \\
\hline SD: Standard deviation & \\
\end{tabular}

\begin{tabular}{|c|c|c|}
\hline Variable & Father, $\boldsymbol{n}(\%)$ & Mother, $\boldsymbol{n}(\%)$ \\
\hline \multicolumn{3}{|l|}{ Age (years) } \\
\hline Mean (SD) & $44.69(6)$ & $38.92(5.2)$ \\
\hline Range & $32-68$ & $25-66$ \\
\hline Median & 44 & 38 \\
\hline \multicolumn{3}{|l|}{ Education } \\
\hline No education & $24(3)$ & $34(4)$ \\
\hline Primary & $66(9)$ & $87(11)$ \\
\hline Secondary & $77(10)$ & $99(12)$ \\
\hline High school & $186(24)$ & $218(27)$ \\
\hline College/university & $426(55)$ & $360(45)$ \\
\hline \multicolumn{3}{|l|}{ Occupation } \\
\hline Manager & $60(7.5)$ & $12(1.5)$ \\
\hline Professional job & $111(13.8)$ & $23(2.9)$ \\
\hline Business/self-employed & $139(17.3)$ & $4(0.5)$ \\
\hline Administrative & $272(33.9)$ & $76(9.5)$ \\
\hline Education professional & $43(5.4)$ & $79(9.8)$ \\
\hline Military/police & $84(10.5)$ & $2(0.2)$ \\
\hline Elementary/nonskilled job & $24(3)$ & $1(0.1)$ \\
\hline Unemployed/housewife & $46(5.7)$ & $601(74.8)$ \\
\hline Deceased & $24(3)$ & $5(0.6)$ \\
\hline \multicolumn{3}{|l|}{ Family income } \\
\hline $1000-3000 \mathrm{dhs}$ & $85(11)$ & \\
\hline $3000-7000$ dhs & $222(28)$ & \\
\hline$>7000$ dhs & $496(62)$ & \\
\hline
\end{tabular}

between genders demonstrated that girls tended to skip breakfast and preferred sweets and more 
carbohydrates in their diet while boys tended to skip lunch and dinner. Increased frequency of drinks (soft drinks) was found to be more prevalent among boys. As opposed to the Arabs, the Indian population was found to have more regular meals and a healthy and well-nourished diet. The Arab world diet was found to be less healthy and consisted more of fast food, sweets, and foods rich in carbohydrates.

Physical activity frequency was reported to have reduced with age $(P=0.002)$ while sedentary lifestyle increased by age $(P<0.001)$. One to $4 \mathrm{~h}$ daily was reported to be of sedentary activity among Arab population. Activity levels were $66 \%$ among boys and $61 \%$ among girls. As comparison, boys were found to be more physically active (exercising three times/week) than girls (once/week) $(P<0.001)$.

Regarding oral hygiene status, $97.5 \%$ of females were regular in their good hygiene while compared to $89.4 \%$ of males in the study sample. According to the data obtained from the questionnaire, the Arab population brushed their teeth less commonly as opposed to other nationalities. UAE nationals' visits to the dentist were regular and consumed fluoride supplements [Table 3]. Dental visits were found to be least among the Indian population. Oral cleanliness as measured by the BASCD criteria indicated that $95 \%$ of the participants demonstrated a score of 1-6 which states that at least 1-6 regions of the oral cavity (upper left, upper middle, upper right, lower left, lower middle, and lower right) have visible plaque/gingivitis. Remaining $5 \%$ has a score 0 (healthy gums) [Table 4].

The prevalence percentage for obesity and overweight were $14.7 \%$ and $23.5 \%$, respectively, and was found to be highest in the Arab population [Table 5]. The prevalence percentage for dental caries was recorded at $72 \%$ with a mean DMFT score of 3.19 (SD: 2.9), with $25 \%$ caries free [Table 6]. This was once again, recorded as being highest with the Arab population as compared with participants of other nationalities. Mean BMI was recorded at 21. Univariate analysis method was used to calculate an association between DMFT and BMI $(r=0.097, P=0.006)$. The analysis showed that with each extra 10 points in BMI, there was an increase of 0.57 in DMFT score. Multivariate regression models were used to determine the health outcome of BMI and DMFT. Variables such as fathers' education $(P<0.001)$, age of the participants $(P<0.001)$, soft drink consumption $(P<0.001)$, gender $(P=0.008)$, and ethnicity $(P=0.001)$ were all significantly associated with the net value, according to the DMFT predictive value. Similarly, the BMI predictive model demonstrated a similar association of age $(P<0.001)$, school fees $(P=0.005)$, obesity (in the family) $(P<0.001)$, and soft drink consumption $(P<0.001)$ [Table 7].

\section{DISCUSSION}

The present study focuses on the interrelationship of various risk factors of obesity and dental caries

\begin{tabular}{|c|c|c|c|c|c|}
\hline \multirow[t]{2}{*}{ Variable (oral hygiene) } & \multicolumn{4}{|c|}{ Nationality } & \multirow[t]{2}{*}{$P$} \\
\hline & Emirati & Other Arabs & Indian subcontinent & Others & \\
\hline \multicolumn{6}{|l|}{ Toothbrushing } \\
\hline Yes & $307(94.5)$ & $248(89.2)$ & $133(98.5)$ & $62(95.4)$ & 0.002 \\
\hline No & $18(5.5)$ & $30(10.8)$ & $2(1.5)$ & $3(4.6)$ & \\
\hline \multicolumn{6}{|l|}{ Brushing frequency } \\
\hline None & $13(4)$ & $24(8.6)$ & $1(0.7)$ & $2(3.1)$ & $<0.001$ \\
\hline Once & $63(19.4)$ & $88(31.7)$ & $27(20)$ & $17(26.2)$ & \\
\hline Twice & $175(53.8)$ & $127(45.7)$ & $97(71.9)$ & $35(53.8)$ & \\
\hline Three times & $74(22.8)$ & $39(14)$ & $10(7.4)$ & $11(16.9)$ & \\
\hline \multicolumn{6}{|l|}{ Brushing time } \\
\hline None & $13(4)$ & $22(7.9)$ & $1(0.7)$ & $2(3.1)$ & $<0.001$ \\
\hline Morning & $56(17.2)$ & $59(21.2)$ & $30(22.2)$ & $12(18.5)$ & \\
\hline Evening & $14(4.3)$ & $38(13.7)$ & 0 & $7(10.8)$ & \\
\hline Morning and evening & $242(74.5)$ & $159(57.2)$ & $104(77)$ & $44(67.7)$ & \\
\hline \multicolumn{6}{|l|}{ Dental visit last 12 months } \\
\hline Yes & $161(49.5)$ & $141(50.7)$ & $34(25.2)$ & $35(53.8)$ & $<0.001$ \\
\hline No & $164(50.5)$ & $137(49.3)$ & $101(74.8)$ & $30(46.2)$ & \\
\hline \multicolumn{6}{|l|}{ Fluoride tablet } \\
\hline Yes & $100(30.8)$ & $47(16.9)$ & $11(8.1)$ & $7(10.8)$ & $<0.001$ \\
\hline No & $225(69.2)$ & $231(83.1)$ & $124(91.9)$ & $58(89.2)$ & \\
\hline
\end{tabular}


in 10-17-year-old school going children and mean age being 12.8 years (SD: 1.4), residents in Sharjah city, UAE. The demographic characteristics of the parents include mean age of fathers and mothers being 44.69 (SD: 6) and 38.92 (SD: 5.2), respectively. Majority of the parents had university education ( $55 \%$ fathers

\begin{tabular}{|c|c|c|c|}
\hline Variable & $n(\%)$ & Mean & SD \\
\hline \multicolumn{4}{|l|}{ Visible plaque } \\
\hline 0 (healthy gum/no gingivitis) & $40(5)$ & 5.04 & 1.73 \\
\hline 1-5 (region) & $205(25.5)$ & & \\
\hline 6 (all the region) & $558(69.5)$ & & \\
\hline \multicolumn{4}{|l|}{ Unhealthy gums/gingivitis } \\
\hline 0 (no plaque) & $40(5)$ & 5.02 & 1.74 \\
\hline $1-5$ (region) & $210(26.1)$ & & \\
\hline 6 (all the region) & $553(68.9)$ & & \\
\hline
\end{tabular}

\begin{tabular}{|c|c|c|c|c|}
\hline \multirow[t]{2}{*}{ Variables } & \multicolumn{3}{|c|}{ Weight groups } & \multirow[t]{2}{*}{$P$} \\
\hline & Normal $n(\%)$ & Overweight $\boldsymbol{n}(\%)$ & Obese $n(\%)$ & \\
\hline Total weight group & $496(61.8)$ & $118(14.7)$ & $189(23.5)$ & - \\
\hline \multicolumn{5}{|c|}{ Family history of obesity } \\
\hline Yes & $123(24.8)$ & $56(29.6)$ & $67(56.8)$ & \multirow[t]{2}{*}{$<0.001$} \\
\hline No & $373(67)$ & $133(23.9)$ & $51(9.2)$ & \\
\hline \multicolumn{5}{|l|}{ Gender } \\
\hline Male & $242(59.6)$ & $103(25.4)$ & $61(15)$ & \multirow[t]{2}{*}{0.40} \\
\hline Female & $254(64)$ & $86(21.7)$ & $57(14.4)$ & \\
\hline \multicolumn{5}{|l|}{ Nationality } \\
\hline Emirati & $211(64.9)$ & $62(19.1)$ & $52(16)$ & \multirow[t]{4}{*}{0.04} \\
\hline Other Arabs & $154(55.4)$ & $78(28.1)$ & $6(16.5)$ & \\
\hline Indian subcontinent & $89(65.9)$ & $35(25.9)$ & $11(8.1)$ & \\
\hline Others & $42(64.6)$ & $14(21.5)$ & $9(13.8)$ & \\
\hline \multicolumn{5}{|l|}{ School type } \\
\hline Public & $176(65.4)$ & $52(19.3)$ & $41(15.2)$ & \multirow[t]{2}{*}{0.14} \\
\hline Private & $320(59.9)$ & $137(25.7)$ & $77(14.4)$ & \\
\hline \multicolumn{5}{|l|}{ Mother education } \\
\hline No & $20(58.8)$ & $10(29.4)$ & $4(11.8)$ & \multirow[t]{5}{*}{0.49} \\
\hline Primary & $58(66.7)$ & $18(20.7)$ & $11(12.6)$ & \\
\hline Secondary & $69(69.7)$ & $15(15.2)$ & $15(15.2)$ & \\
\hline High school & $127(58.3)$ & $55(25.2)$ & $36(16.5)$ & \\
\hline College & $219(60.8)$ & $91(25.3)$ & $50(13.9)$ & \\
\hline \multicolumn{5}{|l|}{ Father education } \\
\hline No & $16(66.7)$ & $4(16.7)$ & $4(16.7)$ & \multirow[t]{5}{*}{0.21} \\
\hline Primary & $51(77.3)$ & $12(18.2)$ & $3(4.5)$ & \\
\hline Secondary & $44(57.1)$ & $20(26)$ & $13(16.9)$ & \\
\hline High school & $121(65.1)$ & $41(22)$ & $24(12.9)$ & \\
\hline College & $255(59.9)$ & $104(24.4)$ & $67(15.7)$ & \\
\hline \multicolumn{5}{|l|}{ Income } \\
\hline $1000-3000 \mathrm{dhs}$ & $54(63.5)$ & $19(22.4)$ & $12(14.1)$ & \multirow[t]{3}{*}{0.97} \\
\hline $3000-7000$ dhs & $138(62.2)$ & $54(24.3)$ & $30(13.5)$ & \\
\hline$>7000 \mathrm{dhs}$ & $304(61.3)$ & $116(23.4)$ & $76(15.3)$ & \\
\hline
\end{tabular}

and $45 \%$ mothers) with a family income of $>7000$ AED in $62 \%$ of the sample.

While assessing the relationship between dietary habits with obesity in the present study, 51\% had regular meals with included breakfast. According to Brugman et al., ${ }^{[20]}$ having three main meals during the day is more beneficial as it helps to reduce the tendency and frequency of snacking. They also reported that an imbalanced diet is a significant factor for obesity. ${ }^{[21]}$ Similar results were reported by Cho et al., ${ }^{[22]}$ who proved the association between skipping meals (especially breakfast), poor nutrition in the diet, and subsequent obesity. Several other studies showed the same association. Kranz et al. ${ }^{[23]}$ arrived at the result that quality of diet decreases with an increase in age. Similar association (with increase in age) was also found with milk, fruits, and vegetables but soft drink consumption increased. Skipping meals (such 
Khadri, et al.: Risk factors for obesity and dental caries

\begin{tabular}{|c|c|c|c|}
\hline Oral health status & $n(\%)$ & Mean $(95 \% \mathrm{Cl})$ & SD \\
\hline \multicolumn{4}{|l|}{ Total DMFT } \\
\hline $\mathrm{DMFT}=0$ & $197(24.5)$ & $3.19(3.00-3.40)$ & 2.97 \\
\hline DMFT $\geq 1$ & $606(75.5)$ & & \\
\hline \multicolumn{4}{|l|}{ Total D (decayed teeth) } \\
\hline$D=0$ & $228(28.4)$ & $2.75(2.56-2.95)$ & 2.76 \\
\hline$D \geq 1$ & $575(71.6)$ & & \\
\hline Total M (missing teeth) & & & 0.26 \\
\hline$M=0$ & $771(96.0)$ & $0.05(0.03-0.07)$ & \\
\hline$M \geq 1$ & $32(4.0)$ & & \\
\hline Total F (filled teeth) & & & 1.04 \\
\hline $\mathrm{F}=0$ & $659(82.1)$ & $0.38(0.31-0.46)$ & \\
\hline$F \geq 1$ & $144(17.9)$ & & \\
\hline
\end{tabular}

\begin{tabular}{|c|c|c|}
\hline Variables & Coefficient $(95 \% \mathrm{CI})$ & $P$ \\
\hline \multicolumn{3}{|l|}{ Oral hygiene } \\
\hline Visit the dentist & $-0.651(-1.061--0.241)$ & 0.002 \\
\hline Tooth brushing & $0.840(0.017-1.663)$ & 0.045 \\
\hline \multicolumn{3}{|l|}{ Dietary habits } \\
\hline Soft drinks & $0.310(0.149-0.472)$ & $<0.001$ \\
\hline Milk & $-0.131(-0.263--0.001)$ & 0.051 \\
\hline All three main meals & $-0.570(-0.980--0.160)$ & 0.006 \\
\hline Tea and sugar & $0.124(0.011-0.260)$ & 0.071 \\
\hline \multicolumn{3}{|l|}{ Socioeconomic status } \\
\hline Age & $0.420(0.272-0.5677)$ & $<0.001$ \\
\hline Father education & $-0.354(-0.535--0.174)$ & $<0.001$ \\
\hline Gender & $0.415(0.018-0.812)$ & 0.04 \\
\hline Arab & $0.749(0.328-1.171)$ & 0.001 \\
\hline BMI & $0.057(0.016-0.098)$ & 0.006 \\
\hline \multicolumn{3}{|l|}{ All significant variables } \\
\hline Age & $0.344(0.197-0.491)$ & $<0.001$ \\
\hline Soft drink & $0.307(0.162-0.453)$ & $<0.001$ \\
\hline Father education & $-0.333(-0.512--0.153)$ & $<0.001$ \\
\hline Dental visit & $-0.538(-0.927--0.148)$ & 0.012 \\
\hline Gender & $0.544(0.141-0.947)$ & 0.008 \\
\hline All three main meals & $-0.523(-0.917--0.128)$ & 0.009 \\
\hline Tea and sugar & $0.149(0.019-0.279)$ & 0.024 \\
\hline
\end{tabular}

as breakfast) was found to be more predominant in girls (in the present study). This was attributed as a weight control method. However, at the same time, this led to an increase in consumption of mid-morning snacking with high sugar content. Girls skipping breakfast probably is the reason for preference of carbohydrates and sweets among girls while compared to boys in the present study. Brugman et al. ${ }^{[20]}$ reported similar results in their study. According to them,
Dutch girls (4-15 years), in order to maintain their weight and body image, skipped breakfast often. In contrast, in our study, we observed boys skipping lunch/dinner. This could be due to their involvement in outdoor and sporting activates, which could have resulted in higher intake of soft drinks in boys. Hence, the present study concluded that snacking was more common among boys rather than girls.

Another important factor in the present study is the significant difference in preferences of diet and food stuff among different nationalities. While the UAE nationals like their sweets, carbohydrates, and fast food, they tended to have less fruits and vegetables according to Al-Hosani and Rugg-Gunn; ${ }^{[24]}$ this could be due to their high monetary status. Indian population in the UAE were found to have more fruits and vegetables in their diet. This was attributed to the fact that majority of the Indian population is vegetarian unlike the UAE nationals and Arabs. The present study confirmed the results of Vartanian et al., ${ }^{[25]}$ which indicated that increased soft drink intake could reduce milk intake as observed in the present study.

Physical activity in females was linked to cultural and social restrictions according to Henry et al. ${ }^{[26]}$ with the modernization of the world and the change of the traditional Bedouin style living to modern society, let to environmental changes such as the city development and safety of roads. This has greatly affected the opportunities for physical activities. ${ }^{[27]}$ Weather restrictions in the UAE (extreme hot and humid) make it difficult for children to walk to school or play outdoors. Advanced technology in the form of gaming gadgets, in combination with weather restrictions of the country, makes the children prefer more indoor activities such as video games. ${ }^{[26]}$ According to the results of the present study, $60 \%$ of the teenagers had 1-4 h/day of sedentary lifestyle while $27 \%$ had 8 h of such lifestyle. This was again different between nationalities and was found to be higher in the UAE population and least among Indians. Probability factors could be the high dependence on maids among UAE nationals.

Girls had regular brushing habits when compared to boys. This could be due to increased consciousness about personal hygiene among girls as also reported by Rise et al. ${ }^{[28]}$ and Kuusela et al. ${ }^{[29]}$ Both the studies demonstrated that brushing habits were better among 11-year-old girls in 22 European countries and Canada. Adolescents going to public school tend to visit dentist more often as oral care is free for children belonging to UAE nationality. However, children in the private 
schools and the expat population seek treatment in the private sector which is more expensive. Fluoride use, as one of the preventive measures implemented by the Ministry of Health, UAE, was popular among public schools. The present study reported gingivitis being present in $95 \%$ of the children examined while only $5 \%$ of them had healthy gums. The findings are in correlation with previous studies done on schoolchildren in Sharjah, UAE, also reporting a high percentage of children with gingivitis. ${ }^{[30]}$

The percentage of overweight and obesity in the present study was $23.5 \%$ and $14.7 \%$. This was calculated using IOTF cutoff point among students. However, Al-Haddad et al., ${ }^{[8]}$ in a similar study, reported a lower value. However, in their study, they used a US cutoff point to calculate the prevalence rates. Moreover, the study was conducted among the population of Ras al-Khaimah, another emirate in the UAE. The results of this study (6-16 years) reported $9 \%$ for overweight and $8 \%$ for obesity. It is not possible to compare due to the differences in the time period, ages, reference value, and location of the participants. In Abu Dhabi, Dubai, and Al-Ain, ${ }^{[16]}$ the prevalence rate for overweight and obesity is to be $22 \%$ and $14 \%$ (5-17 years old) in comparison to $25 \%$ (overweight) and 15\% (obesity) in males and $22 \%$ (overweight) and $14 \%$ (obesity) for females in the present study. Similar studies conducted by El-Hazmi and Warsy ${ }^{[31]}$ and $\mathrm{Al}-\mathrm{Isa}^{[32]}$ reported higher prevalence of overweight and obese in females while compared to males. However, in the present study, although not significant, the percentages of overweight and obesity were higher in boys when compared to girls.

A study conducted by Jebb et al. ${ }^{[33]}$ reported a racial difference in the prevalence of obesity in the United Kingdom. Reasons to explain this discrepancy across various ethnic groups and nationalities are challenging and complex. One can say that this could be deference in lifestyle among different nationalities. Similarly, we observed that a higher proportion of UAE nationals were obese when compared to Indians living in the UAE. Based on our study and previous prevalence studies, overweight and obesity among participants in the UAE is high. ${ }^{[8,9]}$ One way of explaining this (as mentioned earlier) could be the high monetary status in the UAE as compared to other middle eastern countries. Thus, the people of the UAE are able to afford a more affluent yet sedentary lifestyle and eating habit. According to Knai et al., ${ }^{[34]}$ economic growth and modernization has led to a change in the dietary pattern with increased risk to health issues but at the same time improving living standards. In our study, the type of the school (private/public) the participants were enrolled in did not reflect their economic status, and hence, we could not find a difference in obesity values between them.

In the present study, $72 \%$ of $11-17$-year-old children in Sharjah, UAE, were affected by dental caries, and findings similar to this have been reported by El-Nadeef et al., ${ }^{[13]}$ indicating dental caries prevalence to be $54 \%$ among children aged $12 \%$ and $65 \%$ among children aged 15 years in the UAE. Adolescents living in the UAE belonging to other Arab countries had the highest mean DMFT of 3.73, with a prevalence of $82 \%$, as compared to UAE citizens (DMFT $=3.01,69 \%$ ). Indian adolescents in the UAE had the lowest mean DMFT of 2.38 and a prevalence of $58 \%$. Similar dental caries difference due to ethnicity has also been studied by Dye et al., ${ }^{[35]}$ they stated that this could be due to the fact that different cultural backgrounds influence different dietary habits.

The present study assessed the correlation among dental caries and obesity by examining the risk factors common to both. A positive association was found between the two using the univariate analysis; however, when applying multivariate regression analysis, the results showed that BMI lost its significance when other variables (economic status, food habits, and oral cleanliness status) were considered and the other covariates were controlled. Fathers' educational level and intake of carbonated beverage and juices were identified as significant risk factor for development of dental caries. Therefore, in this study, we could observe that a lower level of parental education had an influence on the child's food choices and lifestyle. Marshall et al. ${ }^{\left[{ }^{[6]}\right.}$ conducted a similar study in the US among 5-7 and 8-11 years old. In this study, they also explored the association of obesity with dental caries and the risk factors. According to them, families with low income, low parental education, overweight mothers, and increased soft drink consumption $(P<0.05)$ had increased dental caries rate. However, in the final statistical analysis, mothers' education was the only significant variable.

Multivariate regression analysis on BMI predictive model showed a positive significance with age, school fees, obesity in family, and soft drink consumption. Individuals' genes have been implemented as risk factors for obesity. ${ }^{[37]}$ The present study showed the same. Any bias need to be removed, with caution, as the history of overweight in the family, was 
self-reported by the participating adolescents. A positive significant link was suggested by the present study between soft drink consumption and BMI. According to Malik and Bakir, ${ }^{[16]}$ with similar findings, the explanation is that soft drinks are a high source of sugar. This intake can replace the necessary nutritious food in the diet. Thus, they tend to provide empty calories in small volumes by increasing the overall energy intake ${ }^{[38]}$ Furthermore, they decrease/replace the consumption of milk. ${ }^{[25]}$ In our study, soft drink alone is an important factor in calorie intake and in development of obesity and dental caries.

\section{CONCLUSIONS}

The present study concluded that correlation was found between obesity and dental caries using univariate analysis. However, soft drink was the main contributing factor for both obesity and BMI, according to the multivariate model.

\section{Financial support and sponsorship \\ Nil.}

\section{Conflicts of interest}

There are no conflicts of interest.

\section{REFERENCES}

1. WHO. Diet, Nutrition and the Prevention of Chronic Disease. Technical Report Series No. 916. Geneva: World Health Organization/Food and Agriculture Organization; 2003.

2. Drewnowski A. Fat and sugar: An economic analysis. J Nutr 2003;133:838S-40S.

3. Drewnowski A. Nutrition transition and global dietary trends. Nutrition 2000;16:486-7.

4. Kopelman PG. Obesity as a medical problem. Nature 2000;404:635-43.

5. Al-Sendi AM, Shetty P, Musaiger AO. Prevalence of overweight and obesity among bahraini adolescents: A comparison between three different sets of criteria. Eur J Clin Nutr 2003;57:471-4.

6. al-Mahroos F, al-Roomi K. Overweight and obesity in the arabian peninsula: An overview. J R Soc Promot Health 1999;119:251-3.

7. Al-Rukban MO. Obesity among Saudi male adolescents in Riyadh, Saudi Arabia. Saudi Med J 2003;24:27-33.

8. Al-Haddad F, Al-Nuaimi Y, Little BB, Thabit M. Prevalence of obesity among school children in the United Arab Emirates. Am J Hum Biol 2000;12:498-502.

9. Al-Haddad FH, Little BB, Abdul Ghafoor AG. Childhood obesity in United Arab Emirates schoolchildren: A national study. Ann Hum Biol 2005;32:72-9.

10. Utter J, Scragg R, Schaaf D, Mhurchu CN. Relationships between frequency of family meals, BMI and nutritional aspects of the home food environment among New Zealand adolescents. Int J Behav Nutr Phys Act 2008;5:50.

11. Moynihan P. Nutritional impact in oral health promotion. Oral Health Prev Dent 2003;1 Suppl 1:385-401.

12. Gerdin EW, Angbratt M, Aronsson K, Eriksson E, Johansson I. Dental caries and body mass index by socio-economic status in Swedish children. Community Dent Oral Epidemiol 2008;36:459-65.

13. El-Nadeef MA, Al Hussani E, Hassab H, Arab IA. National survey of the oral health of 12- and 15-year-old schoolchildren in the United Arab Emirates. East Mediterr Health J 2009;15:993-1004.

14. Hooley M, Skouteris H, Boganin C, Satur J, Kilpatrick N. Body mass index and dental caries in children and adolescents: A systematic review of literature published 2004 to 2011. Syst Rev 2012;1:57.

15. Saarloos D, Kim JE, Timmermans H. The built environment and health: Introducing individual space-time behavior. Int J Environ Res Public Health $2009 ; 6: 1724-43$.

16. Malik M, Bakir A. Prevalence of overweight and obesity among children in the United Arab Emirates. Obes Rev 2007;8:15-20.

17. Hilgers KK, Kinane DE, Scheetz JP. Association between childhood obesity and smooth-surface caries in posterior teeth: A preliminary study. Pediatr Dent 2006;28:23-8.

18. WHO. Oral Health Survey: Basic Mehods. $4^{\text {th }}$ ed. Geneva: World Health Organization; 1997a.

19. Pitts NB, Evans DJ, Pine CM. British Association for the Study of Community Dentistry (BASCD) diagnostic criteria for caries prevalence surveys-1996/97. Community Dent Health 1997;14 Suppl 1:6-9.

20. Brugman E, Meulmeester JF, Spee-Van der Wekke A, Verloove-Vanhorick SP. Breakfast-skipping in children and young adolescents in The Netherlands. Eur J Public Health 1998;8:325-8.

21. Croezen S, Visscher TL, Ter Bogt NC, Veling ML, Haveman-Nies A. Skipping breakfast, alcohol consumption and physical inactivity as risk factors for overweight and obesity in adolescents: Results of the E-MOVO project. Eur J Clin Nutr 2009;63:405-12.

22. Cho S, Dietrich M, Brown CJ, Clark CA, Block G. The effect of breakfast type on total daily energy intake and body mass index: Results from the Third National Health and Nutrition Examination Survey (NHANES III). J Am Coll Nutr 2003;22:296-302.

23. Kranz S, Findeis JL, Shrestha SS. Use of the Revised Children's Diet Quality Index to assess preschooler's diet quality, its sociodemographic predictors, and its association with body weight status. J Pediatr (Rio J) 2008;84:26-34.

24. Al-Hosani E, Rugg-Gunn A. Combination of low parental educational attainment and high parental income related to high caries experience in pre-school children in Abu Dhabi. Community Dent Oral Epidemiol 1998;26:31-6.

25. Vartanian LR, Schwartz MB, Brownell KD. Effects of soft drink consumption on nutrition and health: A systematic review and meta-analysis. Am J Public Health 2007;97:667-75.

26. Henry CJ, Lightowler HJ, Al-Hourani HM. Physical activity and levels of inactivity in adolescent females ages 11-16 years in the United Arab Emirates. Am J Hum Biol 2004;16:346-53.

27. Kirk SF, Penney TL, McHugh TL. Characterizing the obesogenic environment: The state of the evidence with directions for future research. Obes Rev 2010;11:109-17.

28. Rise J, Haugejorden O, Wold B, Aarö LE. Distribution of dental health behaviors in nordic schoolchildren. Community Dent Oral Epidemiol 1991;19:9-13.

29. Kuusela S, Honkala E, Kannas L, Tynjälä J, Wold B. Oral hygiene habits of 11-year-old schoolchildren in 22 European countries and Canada in 1993/1994. J Dent Res 1997;76:1602-9.

30. Gopinath VK, Rahman B, Awad MA. Assessment of gingival health among school children in Sharjah, United Arab Emirates. Eur J Dent 2015;9:36-40.

31. El-Hazmi MA, Warsy AS. A comparative study of prevalence of overweight and obesity in children in different provinces of Saudi Arabia. J Trop Pediatr 2002;48:172-7.

32. Al-Isa AN. Body mass index, overweight and obesity among Kuwaiti intermediate school adolescents aged 10-14 years. Eur J Clin Nutr 2004;58:1273-7.

33. Jebb SA, Rennie KL, Cole TJ. Prevalence of overweight and obesity among young people in Great Britain. Public Health Nutr 2004;7:461-5.

34. Knai C, Suhrcke M, Lobstein T. Obesity in Eastern Europe: An overview of its health and economic implications. Econ Hum Biol 2007;5:392-408.

35. Dye BA, Shenkin JD, Ogden CL, Marshall TA, Levy SM, Kanellis MJ, et al. The relationship between healthful eating practices and dental caries in children aged 2-5 years in the United States, 1988-1994. J Am Dent Assoc 2004;135:55-66.

36. Marshall TA, Eichenberger-Gilmore JM, Broffitt BA, Warren JJ, Levy SM. Dental caries and childhood obesity: Roles of diet and socioeconomic status. Community Dent Oral Epidemiol 2007;35:449-58.

37. Bouchard C. Childhood obesity: Are genetic differences involved? Am J Clin Nutr 2009;89:1494S-501S.

38. Gaby AR. Adverse effects of dietary fructose. Altern Med Rev 2005;10:294-306. 